\title{
O SISTEMA BRASILEIRO DE GERENCIAMENTO DOS RECURSOS HÍDRICOS: Uma Proposta Democrática e Participativa no Tratamento da Água
}

\begin{abstract}
Fernanda Serrer
Mestre pela Universidade Regional do Noroeste do Estado do Rio Grande do Sul - Unijuí. Professora do curso de Graduação em Direito da Unijuí. fernanda.serrer@unijui.edu.br
\end{abstract}

\section{Marcos Paulo Scherer}

Mestre pela Universidade Regional do Noroeste do Estado do Rio Grande do Sul - Unijuí. Professor dos cursos de Graduação em Administração e Agronomia da Setrem Três de Maio (RS). Presidente do Comitê de Bacia Hidrográfica dos Rios Turvo, Santa Rosa e Santo Cristo (Gestão 2014-2016).marcospscherer@hotmail.com

\section{Resumo}

Diante da grave crise ecológica vivida atualmente, principalmente em relação aos recursos hídricos e às grandes transformações políticas que vêm sofrendo os Estados nacionais em uma nova conformação sociopolítica mundial, faz-se necessário uma reflexão acerca do tratamento que é destinado aos recursos naturais, mais ainda em relação à água, que é um recurso natural vital. 0 presente trabalho discute os efeitos nefastos do processo econômico de mercantilização dos recursos hídricos e seus impactos sobre as populações mais pobres e apresenta a água como recurso natural vital e não como simples mercadoria, discutindo a maneira como ela deve ser administrada e gerenciada para que possa atender às necessidades básicas da vida humana e animal. No mesmo sentido, trata das políticas públicas brasileiras em âmbito federal e estadual para os recursos hídricos, com a introdução de um Sistema de Gerenciamento por Bacia Hidrográfica, mostrando de que forma esse sistema poderá ser mais ou menos eficaz na destinação e controle do uso das águas, inclusive com a instituição do mecanismo de cobrança pela água, visando à democratização do acesso ao recurso hídrico.

\section{Palavras-chave}

Água. Crise. Mercantilização. Democracia. Sistema de gerenciamento. 


\section{THE BRAZILIAN SYSTEM OF HYDROUS RESOUCES MANAGEMENT: A DEMOCRATIC AND PARTICIPATORY PROPOSAL FOR WATER TREATMENT}

\section{Abstract}

Due to the serious ecological crisis currently experienced, mainly related to the water resources and to the major political changes that the states have been suffering in the new world socio-political conformation, it is necessary to reflect on the treatment that is intended to natural resources, regarding water, which is a vital natural resource. This paper discusses the adverse effects of water resources economic commodification process and its impact on the poorest populations. Presents water as a vital natural resource and not as a commodity, discussing how the water should be administered and managed so that it can meet the basic needs of human and animal life. It presents water as a vital natural resource and not as a commodity, discussing how water should be administered and managed so that it can meet the basic needs of human and animal life. In the same way, it deals with the Brazilian public policy at the federal and state levels for Water Resources, with the implementation of a Management System for Watershed, showing how this system may be more or less effective in the allocation and control of water use, including the implementation of the water charging mechanism, in order to democratize the access to water resources.

\section{Keywords}

Water. Crisis. Commercialization. Democracy. Management system.

\section{Sumário}

1 A crise da água e a mercantilização dos recursos hídricos. 20 gerenciamento das águas brasileiro e a busca pela consolidação de um modelo democrático e participativo de tratamento das águas. 3 Conclusão. 4 Referências. 


\section{A CRISE DA ÁGUA E A MERCANTILIZAÇÃO DOS RECURSOS HÍDRICOS}

O surgimento de novos atores internacionais, a influência dos efeitos nefastos e excludentes da globalização econômica, a relativização da soberania ocasionada por essa relaçáo política e econômica mundializada, ante a resposta humanista propagada por organismos internacionais como a ONU e a sua Declaração Universal dos Direitos Humanos, torna ainda mais complexa e difícil a relação do homem com os recursos naturais e o seu gerenciamento.

O grande aumento populacional ocorrido no século 20 e os processos produtivos em larga escala, a produçáo de excedentes e, consequentemente, de resíduos poluentes decorrentes destes processos produtivos e do consumo exacerbado, ocasionam uma excessiva degradação do meio ambiente, que impacta e afeta diretamente os mananciais aquáticos.

Conforme dados divulgados pelo Fundo de População das Naçóes Unidas (UNFPA) (Fundo..., 2013), a população mundial, consistente no número total de habitantes do Planeta, atingiu em 2013, a marca de 7,2 bilhôes de habitantes. No gráfico a seguir, onde é possível visualizar mais bem os dados, percebe-se que a populaçáo mundial demorou 125 anos para passar do primeiro para o segundo bilhão. Já para atingir o terceiro bilhão foram necessários apenas 34 anos. Passados 13 anos, a população mundial já atingiu os 4 bilhôes de habitantes e, mais 13 anos depois, novo bilhão, atingindo cinco bilhôes de pessoas a ocupar o Planeta, para, enfim, em 2013, ter alcançado os mais de 7,2 bi supramencionados.

\section{Evolução do crescimento da população mundial}

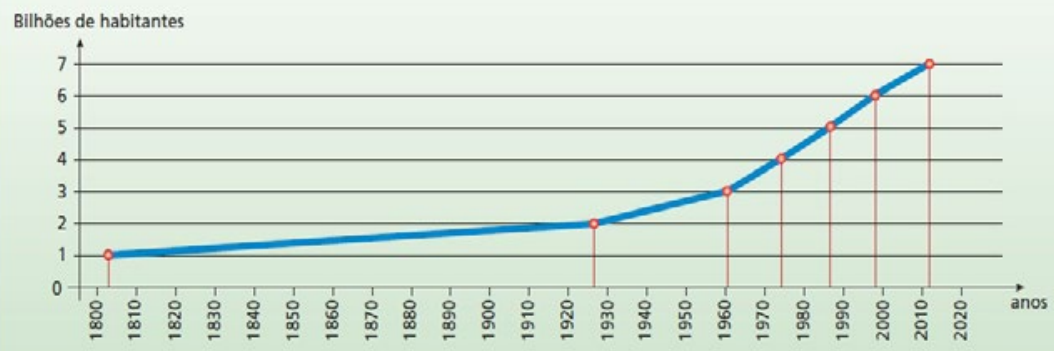

Fonte: $\mathrm{O}$ autor, com base em dados da ONU. 
Com tal constatação, é inegável o surgimento de inúmeras dificuldades para que se possa acomodar essa populaçáo toda no mesmo território em que, há apenas cem anos antes, vivam menos de $25 \%$ da população atual. Para atender às necessidades básicas do imenso contingente populacional, foi preciso o desenvolvimento de políticas expansionistas de produção de alimentos, de utilização de água e de recursos naturais e minerais tratados como insumos necessários ao sistema produtivo.

Sob outro vértice, para consumir toda a produção que se pretendia com o novo sistema produtivo, o próprio sistema incentivou essa multiplicação populacional, pois, quanto mais pessoas, mais consumo e mais demanda, gerando lucros aos proprietários dos meios produtivos e mais mão de obra para realimentar o sistema de produção.

Nesse contexto, a água vem sendo ressignificada. Como insumo essencial à manutenção dos mais diversos processos produtivos característicos do modelo de produçáo capitalista, que nas últimas décadas foi alçado em âmbito global graças ao fenômeno da globalização econômica, a água deixa de ser tratada como propriedade pública, bem de uso comum gerido pelos Estados, para ser considerada um bem privado, a ser livremente extraído e comercializado por empresa multinacionais. Como menciona Vandana Shiva (2006, p. 35),

A economia globalizada está mudando a definição da água, de propriedade pública para um bem privado [...]. A ordem econômica global pede a remoçáo de todos os limites no uso e na regulamentaçáo da água e o estabelecimento de mercados desse recurso. Proponentes do livre comércio da água vêem os direitos da propriedade privada como a única alternativa para a posse estatal e os mercados livres como o único substituto para a regulamentação burocrática das reservas de água.

Revisitando a história da formação das primeiras grandes civilizações, percebe-se que dois recursos naturais básicos foram essenciais para seus desenvolvimentos: a terra e a água. Onde houvesse água em abundância a terra seria fértil, de modo que o homem poderia plantar, colher, criar animais, abandonando, gradativamente, o nomadismo para poder controlar a produção de alimentos. Como destaca Bruni (1994, p. 56), 
As primeiras grandes civilizaçóes surgiram nos vales dos grandes rios - vale do Nilo no Egito, vale do Tigre-Eufrates na Mesopotâmia, vale do Indo no Paquistão, vale do Rio Amarelo na China. Todas essas civilizaçóes construíram grandes sistemas de irrigação, tornaram o solo produtivo e prosperaram. Essas civilizaçóes desmoronaram quando o abastecimento de água se extinguiu ou foi mal aproveitado.

Como lembra Shiva (2006), ao contrário da acepção da água como mercadoria, como bem a ser explorado em favor de interesses de mercado, historicamente o direito de acessar as águas era definido, de modo natural, pelos limites dos ecossistemas e pelas necessidades dos povos, o que explica a formaçáo de povoamentos humanos e civilizaçóes ao longo dos cursos d'água.

A autora indiana destaca a existência nas civilizaçóes antigas de um direito natural à água, na forma de uma doutrina do direito ribeirinho, ou seja, o direito natural dos habitantes, mantidos por um sistema de águas fluviais, de usar a água e não de possuí-la. Menciona que o direito de acessar a água nasce na natureza humana, nas condiçóes históricas de um determinado agrupamento humano e nas necessidades vitais. $\mathrm{O}$ direito à água não decorre de prévio reconhecimento estatal, mas surge da existência humana em um dado contexto ecológico (Shiva, 2006).

Fato é que o direito moderno, sob a influência do racionalismo científico, tratou de abandonar a doutrina do direito ribeirinho instituindo em normas e princípios gerais a doutrina da apropriaçáo, a qual estabeleceu o direito de propriedade da água, de vendê-la e de comercializá-la. A água, como coisa passível de apropriação e valor econômico, é vista como elemento, como substância, como um corpo, muito importante, é certo, mas sem sentido, sem alma, desconectada de sua natural vitalidade.

A precificação, coisificação e apropriação dos recursos hídricos têm no argumento do náo desperdício e dos altos custos agregados ao armazenamento, captação, tratamento e distribuição da água, forte sustentação. Nesse sentido, desde 1992, com a Declaração de Dublin, se estabeleceu que os recursos hídricos de um país são um bem de valor, limitados e vulneráveis e que o náo reconhecimento desse princípio-chave tem contribuído para o desperdício do recurso e seu uso prejudicial ao meio ambiente (Granzieira, 1993). 
É claro que não se pode ignorar que a água é um recurso esgotável, necessitando de altos investimentos financeiros. No caso do Brasil ainda notadamente tais investimentos estão sob o encargo dos Estados da federação, os quais agem por intermédio de empresas concessionárias responsáveis por seu tratamento e distribuição, restando repassados aos usuários os custos de financiamento e manutenção do sistema de abastecimento público, em especial para aqueles que se valem do recurso como insumo de cadeias produtivas. Ocorre que, sob o mesmo argumento de que apenas cobrando pelo uso da água é possível um despertar de consciência preservacionista, vem se consolidando o mercado das águas. Como destaca Amorin (2015, p. 202, grifo do autor),

Essa mercantilização refere-se tanto às preocupaçôes recentes em relação à privatização e comercializaçẫo dos serviços de captação, tratamento, distribuiçấo e dessalinizaçáo, quanto à comercializaçáo da água engarrafada, em todas as suas variantes e da própria água em si, in natura, sem qualquer tipo de processo de industrialização ou manufatura.

Como mercadoria, a água doce é inserida na moldura jurídica internacional. Tratada como um commodity, precificável e passível de apropriação privada, a regulamentação de sua circulação entre sujeitos do comércio internacional é feita por um ordenamento jurídico internacional de comércio.

O regime jurídico de comércio internacional tem seu primeiro e mais importante marco regulatório no Acordo Geral sobre Tarifas e Comércio, ou General Agreement on Tariffs and Trade (GATT). Firmado em 1947 na Rodada Comercial de Genebra, o GATT tem como propósito harmonizar as políticas aduaneiras e impulsionar a liberalização comercial, combatendo práticas protecionistas entre os Estados signatários. Em 1986, na Rodada do Uruguai, foi o responsável pela criação da Organização Mundial de Comércio (OMC), encarregada de efetivar e garantir a aplicação dos acordos celebrados nas rodadas anteriores (General..., 1994).

Nesse cenário regulatório internacional, apesar de não haver disposição taxativa expressa do conceito jurídico de mercadoria, e, por consequência da classificação da água como mercadoria, adverte Matsumi Katsuoka (apud Amorin, 2015) que as regras comerciais internacionais não excluem a água doce como mercadoria e já 
apontam a possibilidade de seu tratamento como tal. De modo sutil, diz o autor, o direito do comércio internacional tem conferido um tratamento jurídico à água como mercadoria.

Ilustrando os encaixes normativos existentes e utilizados no comércio internacional para conferir tratamento de mercado aos recursos hídricos, Amorin (2015) lembra que, em 1983, em Bruxelas, foi aprovada a Convenção Internacional sobre o Sistema Harmonizado de Designação e Codificação de Mercadorias, ou simplesmente Harmonized System (HS).

A Codificação prevista no HS, utilizada amplamente por mais de 177 países, dentre eles o Brasil, a Comunidade Andina e o Mercosul, tem sua maior aplicação no estabelecimento de nomenclaturas e códigos uniformes de enquadramento aduaneiro de mercadorias transnacionais no comércio internacional. Assim, o que estiver codificado pelo HS o foi porque o mercado e as regras jurídicas do comércio internacional lhe consideram mercadoria. A água doce possui codificação expressa no HS, em seu capítulo 22, que trata das bebidas e similares.

No código HS 22.01 estão as "águas, incluídas as águas minerais, naturais ou artificiais, e as águas gaseificadas, não adicionadas de açúcar, ou de outros edulcorantes, nem aromatizadas; gelo e neve" e no código 22.02 incluem-se "as águas minerais e as águas gaseificadas, adicionadas de açúcar ou de outros edulcorantes ou aromatizadas, e outras bebidas não alcoólicas, exceto sucos de frutas”.

Assim, diante da constatação da existência de um tratamento mercantil para a água doce conferido pelo regime jurídico do comércio internacional multilateral, os Estados nacionais deixam de ser protagonistas na definição dos rumos das águas interiores e passam a coadjuvantes do sistema de mercado, recebendo do próprio sistema falaciosos auxílios para a proteção de suas águas, desde que condicionados à não imposição de restriçóes quantitativas à importação e exportação de mercadorias. Basta ver, nesse sentido, o disposto no artigo XI, do GATT-47, que estabelece expressamente:

Nenhuma proibição ou restrição exceto taxas aduaneiras, taxas ou outras tarifas, quer seja imposta através de quotas, licenças de importação ou exportação ou outras medidas, serão impostas ou mantidas por qualquer parte contratante 
na importação de qualquer produto proveniente do território de outra parte contratante ou na exportaçáo ou venda para a exportação de qualquer produto destinado ao território de outra parte contratante.

No conceito de água doce como mercadorias, ainda estáo os projetos de privatização em serviços de água. Como lembra Shiva (2006), no tópico privatização das águas o Banco Mundial e outras agências de fomento vêm financiando projetos sob o rótulo das parcerias público-privadas para setores de construção de infraestrutura e gerenciamento de serviços de captação, tratamento e distribuição das águas.

Sob o forte argumento da necessidade de atrair capitais da iniciativa privada sem sopesar o Estado com a criação de empregos públicos quando se trata de captação, tratamento e distribuição das águas, adverte Petrella (2002) que o Banco Mundial vem apostando que os países do Terceiro Mundo, até o ano de 2025, estarão completamente urbanizados e que se estima serão necessários 600 bilhões de dólares de investimentos em projetos de infraestrutura, dentre os quais a instalação de sistemas de captação e esgotamento das águas.

Esse modelo de privatização das águas, como resultado exitoso das políticas do Banco Mundial, acaba por corroer os direitos à água e ao acesso democrático das pessoas à água, e torna o recurso inacessível aos pobres.

No Chile, a Suez Lyonnaise des Eaux insistiu numa margem de lucro de trinta e cinco por cento. Em Casablanca, consumidores viram o preço da água triplicar. $\mathrm{Na}$ Grã-Bretanha, as contas de água e esgoto subiram sessenta e sete por cento entre 1989-90 e 1994-95. O índice de desligamento dos serviços das pessoas aumentou em cento e setenta e sete por cento. Na Nova Zelândia, cidadáos foram às ruas protestar contra a comercialização da água. Na África do Sul, o fornecimento de água de Joanesburgo passou a ser controlado pela Suez Lyonnaise des Eaux. Logo a água tornou-se insegura, inacessível e impagável. Milhares de pessoas tiveram a água cortada e infecçôes de cólera tornaram-se incontroláveis (Shiva, 2006, p. 112).

A água é vital. Não existe vida sem ela. Estima-se que em torno de $70 \%$ da constituição do corpo humano seja água. Para se manter com dignidade uma pessoa necessita, em média, 30 litros de água por dia para suprir sua sede, preparar seus alimentos e fazer sua higiene pessoal. $\mathrm{O}$ desapossamento comunitário das 
águas e a mercantilização do recurso hídrico, somados às dificuldades econômicas para acessar democraticamente a água e os limites dos ecossistemas que se revelam naturalmente desiguais quanto à distribuição do recurso, faz com que mais de 34.000 pessoas morram diariamente no mundo em razão de doenças relacionadas à falta ou má qualidade da água (Weyrmüller, 2014).

Atualmente, a realidade da crise da água se torna um problema essencial e globalizado. Como menciona Tundisi (2011), no limiar do século 21, entre outras tantas crises, a do acesso aos recursos hídricos, ou somente crise hídrica, é uma ameaça à manutenção da humanidade e à sobrevivência da biosfera. Segundo estimativas dos órgãos integrantes das Naçôes Unidas, atualmente

Cerca de 700 millones de personas procedentes de 43 países diferentes sufren escasez de agua. En 2025, 1.800 millones de personas vivirán en países o regiones con escasez absoluta de agua y dos terceras partes de la población mundial podrían hacerlo en condiciones de estrés hídrico. Bajo el contexto actual de cambio climático, en el 2030, casi la mitad de la población mundial vivirá em áreas de estrés hídrico, incluidos entre 75 y 250 millones de personas de África. Además, la escasez de agua en áreas áridas o semiáridas provocará el desplazamiento de entre 24 y 700 millones de personas. Em el África Subsahariana se concentra el mayor número de países con estrés hídrico (Naciones Unidas, 2012).

Diante da crise da água e da negação ao acesso ao recurso para as pessoas que não têm condiçóes de pagar o preço que impóe o mercado, a questão que fica é saber se a referida crise é, de fato, uma crise ecológica ou de mercado.

A imposição de preços elevados sob condiçôes de livre-mercado não levarão à conservação do recurso. Diante das enormes desigualdades econômicas, é muito provável que os economicamente mais fortes desperdiçarão água, enquanto os pobres pagarão a conta do desperdício. Assim, melhor concluir que a crise da água "é uma crise ecológica com causas comerciais, mas sem soluçôes de mercado. As soluçóes de mercado destroem a terra e agravam a desigualdade" (Shiva, 2006, p. 32).

No contradiscurso do mercado, a Assembleia Geral da Organização das Naçóes Unidas (ONU), em julho de 2010, após mais de uma década de debates, declarou o acesso à água potável e às instalaçóes sanitárias como direitos humanos pela Resolução da Assembleia Geral ONU A/RES/64/292. Pela primeira vez, esta 
Resolução da ONU reconhece formalmente o "direito à água e ao saneamento" e reconhece que "a água potável limpa e o saneamento são essenciais para a concretização de todos os direitos humanos". A Resolução apela aos Estados e às organizaçóes internacionais que

providenciem os recursos financeiros, contribuam para o desenvolvimento de capacidades e transfiram tecnologias de modo a ajudar os países, nomeadamente os países em vias de desenvolvimento, a assegurarem água potável segura, limpa, acessível e a custos razoáveis e saneamento para todos (Organização..., 2012).

A Organização das Naçôes Unidas para a Educação, Ciência e Cultura (Unesco) emitiu, no ano de 2005, a Resolução A/Res/58/217, proclamando o período de 2005 a 2015 como a Década Internacional para Ação "Água, Fonte de Vida” iniciando-se no Dia Mundial da Água - 22 de março de 2005 (Organização..., 2015).

A Resolução afirma que o objetivo principal da década deve ser um foco maior nas questôes relacionadas à água em todos os níveis. Menciona, ainda, a criação de programas relacionados à água de forma a atingir os objetivos acordados internacionalmente sobre questóes ligadas à água contidos na Agenda 21, nos Objetivos de Desenvolvimento do Milênio das Naçóes Unidas e no Plano de Implementação de Johannesburgo (Organização..., 2015).

Com essa recente decisão da Assembleia Geral de conferir à água potável e ao saneamento básico o status de direito fundamental, pode-se esperar que a situação comece a tomar um novo rumo, uma vez que a visão da água como um bem natural dotado de valor econômico não serve como paradigma do acesso facilitado ao recurso para os mais necessitados.

Mais do que isso, a proteção dos recursos ambientais, em especial da água doce, não pode ser assegurada pela lógica do mercado. Ela exige a recuperação do significado da água como elemento vivo, como uma substância material primordial, concebida como o princípio, a origem de todas as coisas.

Ainda não se pode esquecer que o ser humano também acentua a crise quando deixa de gerenciar adequadamente os recursos hídricos e, também, quando negligencia na formulação de uma orientação política mundial de preservação e 
conservação ambiental, que englobaria as águas transfronteiriças e interiores. Esse retrato da realidade é comum tanto em países do continente europeu, africano e asiático, quanto em alguns países latino-americanos, onde

[...] há apenas uns 20 ou 30 anos, as águas domésticas ou industriais usadas eram, em geral, lançadas nos rios, sem qualquer forma de tratamento. Os rios que atravessavam as grandes cidades muito se tornaram esgotos a céu aberto, com ecossistemas aquáticos totalmente deteriorados (Marsily, 1994, p. 89).

Do ponto de vista jurídico, a água precisa ser tratada como recurso comum, bem de uso comum, juridicamente protegido pelos Estados e democraticamente gerenciado pelas comunidades. Como menciona Shiva (2006), os movimentos de conservação da água estão dando mostras de que a verdadeira solução para a crise da água está na energia, no tempo, no trabalho e no valor da solidariedade das pessoas. Encerra a autora afirmando que "a guerra por água atual desencadeada por corporaçôes multinacionais só pode ser vencida por movimentos maciços de democracia por água”.

Acabar com a crise da água exige o amadurecimento da democracia como um sistema político eficiente, e ainda da cultura de preservação e conservação dos recursos naturais enquanto bens finitos, uma vez que é por meio da democracia que se poderá promover a justiça e por intermédio da proteção que se poderá manter os recursos naturais.

No Brasil, o modelo desenvolvido para a gestão dos recursos hídricos, surgido a partir da Constituição Federal de 1988, segue a lógica democrática do Estado, com a participação dos usuários e da população no estabelecimento das políticas públicas acerca da utilização e cobrança das águas.

\section{GERENCIAMENTO DAS ÁGUAS BRASILEIRO E A BUSCA PELA CONSOLIDAÇÃO DE UM MODELO DEMOCRÁTICO E PARTICIPATIVO DE TRATAMENTO DAS ÁGUAS}

$\mathrm{Na}$ Constituição Federal Brasileira de 1988, nos termos do disposto nos artigos 21 e 22, o legislador constituinte estabeleceu competências para gerenciar e legislar sobre águas. Assim: 
Art. 21. Compete à União:

XIX - instituir sistema nacional de gerenciamento de recursos hídricos e definir critérios de outorga de direitos de seu uso; (Regulamento)

Art. 22. Compete privativamente à União legislar sobre:

IV - águas [...] (Brasil, 2015).

Ou seja, foi determinado pela Constituição Federal que a União instituirá um Sistema Nacional de Gerenciamento de Recursos Hídricos e definirá critérios de outorga para os direitos de uso, competindo, ainda privativamente, à União, legislar sobre as águas. $\mathrm{O}$ regulamento determinado pelo artigo 21 foi inserido no ordenamento jurídico nacional em 1997 pela Lei das Águas, representada pela Lei Federal no 9.433, que, em suma, foi idealizada e praticamente copiada da Lei Gaúcha, Lei no 10.350/94, que estabeleceu, ainda em 1994, a Política Estadual de Recursos Hídricos do Estado do Rio Grande do Sul.

Na norma federal o legislador estabeleceu a Política Nacional de Recursos Hídricos, baseada, principalmente, nos seguintes fundamentos:

Art. 10 A Política Nacional de Recursos Hídricos baseia-se nos seguintes fundamentos:

I - a água é um bem de domínio público;

II - a água é um recurso natural limitado, dotado de valor econômico;

III - em situações de escassez, o uso prioritário dos recursos hídricos é o consumo humano e a dessedentação de animais;

IV - a gestão dos recursos hídricos deve sempre proporcionar o uso múltiplo das águas;

V - a bacia hidrográfica é a unidade territorial para implementação da Política Nacional de Recursos Hídricos e atuação do Sistema Nacional de Gerenciamento de Recursos Hídricos;

VI - a gestão dos recursos hídricos deve ser descentralizada e contar com a participação do Poder Público, dos usuários e das comunidades (Brasil, 2015). 
Com isso, a gestão dos recursos hídricos, devendo ser descentralizada e contando com a participação igualitária e proporcional dos usuários e das comunidades com o Poder Público, viabiliza a democracia participativa para o gerenciamento das águas, conforme previsto em lei. Mais ainda, a água deixa de ser, nesse momento, um bem apropriável e passa a ser um recurso natural limitado, por vezes dotado de valor econômico, bem de domínio público. Determina ainda a Lei das Águas que a gestão deve sempre proporcionar o seu uso múltiplo, com prioridade para o consumo humano e a dessedentação de animais.

A menção de que a água deixa de ser bem privado poderia conduzir à concepção de que a água é um bem de propriedade do Estado ou do governo. Tal entendimento, porém, é falacioso. Por certo,

a dominialidade pública da água não transforma o Poder Público federal e estadual em proprietário da água, mas o torna gestor desse bem, no interesse de todos. Também, por isto, não pode o Governo Federal negar aos Estados e Municípios o poder de dispor, através de leis que atendam situaçóes específicas locais, no sentido de proteger o interesse ambiental de cada regiáo do País (Adede; Castro, 2008, p. 57).

Apesar da existência da lei da Política Nacional dos Recursos Hídricos, ainda há críticos que contestam o efetivo papel do Estado, quando se trata de gestáo das águas doces diante dos demais atores paraestatais. Afirmam que, apesar da existência de leis específicas a respeito da outorga do uso da água, ainda assim a realidade é que as pressóes e reaçóes contrárias são tão fortes, notadamente dos meios de produção industrial e agronegócio, que isto é quase letra morta (Adede; Castro, 2008).

A mesma Lei Federal, no 9.433/97 determina também quem participará do Sistema Nacional de Gerenciamento dos Recursos Hídricos:

I - o Conselho Nacional de Recursos Hídricos;

I-A. - a Agência Nacional de Águas;

II - os Conselhos de Recursos Hídricos dos Estados e do Distrito Federal;

III - os Comitês de Bacia Hidrográfica; 
IV - os órgãos dos poderes públicos federal, estaduais, do Distrito Federal e municipais cujas competências se relacionem com a gestão de recursos hídricos;

V - as Agências de Água (Brasil, 2015).

Eis aí um importante instrumento de gestão e gerenciamento dos recursos hídricos no sistema brasileiro, devendo ser instituído mediante a ampla participação da comunidade por meio da criação de Comitês de Bacia Hidrográfica, que, junto com as demais instituiçôes mencionadas, irão fazer o gerenciamento efetivo, democrático e participativo dos mananciais aquáticos no âmbito de sua área de atuação, em cada bacia hidrográfica ou grupo de bacias.

Ainda segundo a Lei Federal, a composição dos Comitês deve respeitar a descentralizada participação social:

Art. 39. Os Comitês de Bacia Hidrográfica são compostos por representantes:

I - da União;

II - dos Estados e do Distrito Federal cujos territórios se situem, ainda que parcialmente, em suas respectivas áreas de atuação;

III - dos Municípios situados, no todo ou em parte, em sua área de atuação;

IV - dos usuários das águas de sua área de atuação;

$\mathrm{V}$ - das entidades civis de recursos hídricos com atuação comprovada na bacia. (Brasil, 2015, grifo nosso).

Essa formação de Comitês de Bacia Hidrográfica foi assim instituída atendendo ao disposto no artigo $1^{\circ}$ da norma federal, na qual o inciso VI suprarreproduzido exige como fundamento da Política Nacional dos Recursos Hídricos a gestão descentralizada com a participação do Poder Público, dos usuários e das comunidades. 
$\mathrm{Na}$ lei gaúcha, ${ }^{1}$ igualmente está previsto no artigo $3^{\circ}$, III, que os benefícios e os custos para utilização da água devem ser repartidos considerando a complexidade dos interesses e suas possibilidades locais, com a participação dos indivíduos e das comunidades ribeirinhas.

Assim, tanto a lei federal quanto a gaúcha garantem que o gerenciamento efetivo das águas se dará por participação descentralizada e com a mesma força entre o Poder Público Estatal, os usuários das águas (indústrias, agricultores, criadores) e a populaçáo em geral que usa o recurso natural para o abastecimento humano.

O gerenciamento dos recursos hídricos sendo feito por bacia hidrográfica e não por limites geopolíticos, com a participação ativa da sociedade civil organizada, com equilíbrio de forças com o Poder Público é que poderá garantir que a política de recursos hídricos será construída de acordo com a real vontade da população e da comunidade local, atribuindo valor ao bem quando usado como insumo em processos produtivos e garantindo livre-acesso quando a água for apenas um recurso natural vital.

O modelo de gestão democrática, descentralizada e participativa adotado pelo ordenamento brasileiro e gaúcho, parece ser muito próximo de um sistema ideal, mas, provavelmente, possui seus defeitos. Ainda assim, é mais avançado do que muitos outros desenhados por países desenvolvidos. Como assevera Souza Júnior (2004, p. 152-153), a opçấo brasileira por um modelo democrático de "gestão de recursos hídricos, no aspecto restrito à participação social, representa um avanço, conquanto outros países desenvolvidos possuem estruturas bastante centralizadas de gestáo”.

\footnotetext{
${ }^{1}$ Art. $3^{\circ}-$ A Política Estadual de Recursos Hídricos reger-se-á pelos seguintes princípios: II - os benefícios e os custos da utilização da água devem ser equitativamente repartidas através de uma gestấo estatal que reflita a complexidade de interesses e as possibilidades regionais, mediante o estabelecimento de instâncias de participação dos individuos e das comunidades afetadas; [...] (Rio Grande do Sul, 1994).
} 
O grande entrave existente ainda hoje no Sistema Estadual de Recursos Hídricos do Rio Grande do Sul, que é um dos mais adiantados do Brasil, ainda está na vontade política de governantes que, ao deixarem de pôr em prática por completo o Sistema como preconizado em lei, permitem que a água continue sendo livremente explorada e comercializada sem qualquer controle por parte do Estado.

Para que a lei possa ser integralmente executada, com cada um cumprindo seu papel nesse completo Sistema de Gerenciamento, é necessário que todos os organismos previstos na lei de fato existam, ou seja, tenham sido efetivamente criados.

A lei estabelece quatro pilares principais para o funcionamento do Sistema Gaúcho, quais sejam: o Conselho de Recursos Hídricos, o Departamento de Recursos Hídricos, os Comitês de Gerenciamento de Bacia Hidrográfica e as Agências de Região Hidrográfica. O Estado do RS divide-se em três grandes Regiốes Hidrográficas: Região Uruguai, Região Litoral e Região Guaíba.

O Conselho Estadual de Recursos Hídricos - CRH - está criado e efetivamente funcionando, emitindo suas resoluçôes e normatizaçôes acerca da política estadual e das políticas de governo para os recursos hídricos, inclusive fazendo a definição e gestão de uso dos recursos financeiros do fundo estadual de recursos hídricos - FRH -, principalmente provenientes da cobrança pelo uso das águas interestaduais e até estaduais para a geração de hidroeletricidade.

O Departamento de Recursos Hídricos - DRH - é o órgão que representa o Estado diretamente junto ao Sistema de Gerenciamento e tem por função precípua dar o suporte técnico necessário ao Conselho Estadual e aos Comitês de Gerenciamento de Bacias, ao menos até a criação das Agências de Bacia. Ainda, cumpre ao DRH propor ao Conselho os critérios de outorga de uso das águas, bem como a elaboração do Plano Estadual de Recursos Hídricos.

Os Comitês de Gerenciamento de Bacia Hidrográfica devem ser instituídos em cada bacia hidrográfica, dentro das três regiôes, cabendo-lhes a coordenação programática das atividades dos agentes públicos e privados, relacionados aos recursos hídricos, compatibilizando, no âmbito de sua bacia, a crescente melhoria da qualidade das águas com a preservação de suas quantidades e com a aplicação das metas estabelecidas no Plano Estadual dos Recursos. Além disso, a autonomia dos 
comitês de bacia na instituição das agências de bacia, responsáveis pela operacionalização dos instrumentos econômicos de responsabilidade dos comitês, é a garantia da aplicabilidade desses instrumentos na região de abrangência (Souza Junior, 2004).

Para completar definitivamente o Sistema no RS, todavia, faltam as Agências de Bacia, a serem instituídas por Lei como integrantes da Administração Indireta do Estado (artigo 20 da Lei Estadual no 10.350/1994). Às Agências de Bacia cumpre o papel mais prático da gestão. Ou seja, caberá prestar o apoio técnico ao Sistema Estadual de Recursos Hídricos, tendo como principal atribuiçáo a de assessorar e subsidiar tecnicamente os Comitês de Gerenciamento de Bacia Hidrográfica, inclusive os necessários para a fixação dos valores da cobrança pelo uso das águas e pelo rateio dos custos de obras de interesse comum da bacia hidrográfica. Ainda, cumpre às Agências o papel de arrecadar e aplicar os valores correspondentes à cobrança pelo uso das águas de acordo com o Plano de cada bacia hidrográfica, aprovado e estabelecido com a participação dos Comitês.

Esse então é o ponto mais nevrálgico do Sistema para sua derradeira efetivação, pois passados mais de 20 anos desde a aprovação da Lei da Política Estadual de Recursos Hídricos no Estado do Rio Grande do Sul, assim como mais de 18 anos da introdução da Política Federal, ainda hoje não estáo instituídas as Agências de Bacia Hidrográfica, tornando impossível a plena efetivação do Sistema de Gerenciamento dos Recursos Hídricos, com a sistematização da cobrança pelos usos das águas.

Com isso, empresas industriais e comerciais continuam livremente explorando os mananciais de água no território brasileiro, engarrafando e vendendo no mercado a preços altíssimos um recurso natural táo raro, nobre e vital.

Mais que isso, por falta de critérios estabelecidos no âmbito dos Comitês de Gerenciamento, a produção industrial e agropecuária utiliza-se livremente e de graça da água que aos humanos custa táo caro para a manutenção da vida, simplesmente por não haver no Sistema a instituição por lei das Agências, que, como dito, têm o papel de arrecadar e aplicar os recursos provenientes da cobrança e dar o suporte técnico aos Comitês, inclusive acerca dos critérios e valores para a cobrança.

De fato, a sistematização que vem sendo instituída no Brasil acaba sendo uma espécie de sistema híbrido entre os modelos francês e inglês de gestáo/operacionalização, posto que 
Enquanto a gestáo propriamente dita obedece a um esquema socioparticipativo, a operacionalizaçáo preconiza características econômicas neoclássicas, por meio da possibilidade de privatização das empresas públicas de abastecimento e saneamento, além do estabelecimento de mercados de água com base na comercialização de direitos de uso. A retirada do Estado de funçóes que lhe eram tradicionais - no caso, abastecimento e saneamento - mais uma vez colocaria a sociedade em evidência, como determinante do papel público no uso de recursos também públicos. E o fórum para essa influência são os comitês de bacia (Souza Junior, 2004, p. 153-154).

É importante frisar, porém, que a cobrança pelo uso da água deve se dar de forma a exigir dos usuários da água a respectiva contrapartida; não dos consumidores individuais que necessitam da água para sua própria sobrevivência, pois para esses o acesso à água deve representar apenas um direto humano fundamental.

Enquanto, portanto, não houver a vontade política dos governantes, que precisam criar as Agências de Bacia Hidrográfica por lei, não haverá a cobrança pela água de quem realmente deve pagá-la. Não havendo cobrança pela água não haverá também açóes e medidas necessárias para reinvestir os recursos financeiros provenientes desta cobrança em melhorias da qualidade e para o efetivo controle e fiscalização da utilização das águas. O Sistema, que parece ser um modelo próximo ao ideal, ainda possui deficiências sérias, mas que, com um pouco mais de ativismo social que motive o governante a efetivar completamente as instâncias da gestáo, pode servir de modelo a outras naçóes.

\section{CONCLUSÃO}

O acesso à água potável não é uma questão de escolha ou de riqueza, é uma questão de viver ou morrer. A água não é uma mercadoria que pode ser comprada ou vendida para gerar o lucro aos seus exploradores privados, como se fosse uma mercadoria qualquer de consumo. Nesse sentido, o gerenciamento dos recursos hídricos, sendo feito por bacia hidrográfica e não por limites geopolíticos, com a participação ativa da sociedade civil organizada, com equilíbrio de forças com o Poder Público, se mostra possível para a concretização do acesso à água potável como direito humano fundamental. Ressalte-se que a política de recursos hídricos, 
nos moldes participativos previstos pela legislação brasileira, é construída de acordo com a real vontade da populaçáo e da comunidade local, atribuindo valor ao recurso natural quando usado como insumo em processos produtivos e garantindo livre-acesso quando a água for apenas um recurso natural vital.

\section{REFERÊNCIAS}

GENERAL AGREEMENT ON TARIFFS AND TRADE. GATT. Acordo Geral sobre Tarifas e Comércio. Os acordos da OMC como interpretados pelo órgão de solução de controvérsias: efeitos na aplicaçâo das regras do comércio internacional). 1994. Disponível em: <http:// ccgi.fgv.br/sites/ccgi.fgv.br/files/file/2_\%20Acordo\%20Geral\%20sobre\%20Tarifas\%20 e\%20Com\%C3\%A9rcio\%201994\%20(GATT\%201994).pdf>. Acesso em: jul. 2015.

ADEDE Y CASTRO, João Marcos. Água: um direito humano fundamental. Porto Alegre: Núria Fabris Editora, 2008.

AMORIN, José Alberto Alves. Direito das águas: o regime jurídico da água doce no Direito Internacional e no atual Direito Brasileiro. São Paulo: Atlas, 2015.

BARLOW, Maude; CLARKE, Tony. Ouro azul: como as grandes corporaçóes estão se apoderando da água do nosso planeta. Ottawa; Canadá: M. Books do Brasil, 2001.

BRASIL. Palácio do Planalto. Disponível em: <http://www.planalto.gov.br/ccivil_03/leis/ L9433.htm>. Acesso em: 16 jun. 2015.

BRUNI, José Carlos. A água e a vida. In: Tempo Social. Revista de Sociologia da USP, São Paulo, p. 53-65, 1994.

GRANZIEIRA, Maria Luiza Machado. Direito de águas e meio ambiente: aspectos jurídicos-ambientais do uso, gerenciamento e da proteção dos recursos hídricos. São Paulo: Ícone, 1993.

MARSILY, Ghislain de. A água. Lisboa: Instituto Piaget, 1994.

NACIONES UNIDAS. Decenio Internacional para La Accion "El agua fuente de vida" 20052015. 2012. Disponível em: <www.un.org/spanish/waterforlifedecade/scarcity.shtml>. Acesso em: jul. 2015.

ORGANIZAÇÃO DAS NAÇÓES UNIDAS. ONU. 2012. Disponível em: <http://www. onu.org.br/rio20/img/2012/01/agenda21.pdf>. Acesso em: 16 jun. 2015. 
PETRELLA, Riccardo. O manifesto da água: argumentos para um contrato mundial. Petrópolis: Editora Vozes, 2002.

RIO GRANDE DO SUL. Lei Estadual no 10.350/1994. Disponível em: <http://www.al.rs. gov.br/legis/m010/m0100018.asp?hid_idnorma=12501\&texto=>. Acesso em: jul. 2015.

SHIVA, Vandana. Guerra por águas: privatização, poluição e lucro. São Paulo: Radical Livros, 2006.

SOUZA JUNIOR, Wilson Cabral de. Gestão das Águas no Brasil: reflexões, diagnósticos e desafios. São Paulo: Petrópolis, 2004.

TUNDISI, José Galizia. Recursos hidricos no século XXI. São Paulo: Oficina de Textos, 2011).

ORGANIZAÇÃO DAS NAÇÓES UNIDAS PARA A EDUCAÇÃO, CIÊNCIA E CULTURA. Unesco. Resolução A/Res/58/217. Disponível em: <www.unesco.org.br>. Acesso em: ago. 2015 .

FUNDO DE POPULAÇÃO DAS NAÇÓES UNIDAS. Unfpa-Brasil. Disponível em: <http://www.unfpa.org.br/novo/index.php/situacao-da-populacao-mundial>. Acesso em: 21 jun. 2015.

WEYERMÜLLER, André Rafael. Água e adaptação ambiental: o pagamento pelo uso como instrumento econômico e jurídico de proteção. Curitiba: Juruá, 2014.

Recebido em: 17/2/2016

Aceito em: 15/3/2016 